\title{
Assessment of the Management of Diarrhoea Among Children Under Five in Addis Ababa, Ethiopia
}

This article was published in the following Dove Press journal:

Pediatric Health, Medicine and Therapeutics

\author{
Arega Gashaw Tsige (D) \\ Teshome Nedi $\left.{ }^{2}\right)^{2}$ \\ Tigist Bacha (D) $^{3}$ \\ 'Department of Pharmacy, College of \\ Health Sciences, Mekelle University, \\ Mekelle, Ethiopia; ${ }^{2}$ Department of \\ Pharmacology and Clinical Pharmacy, \\ College of Health Sciences, Addis Ababa \\ University, Addis Ababa, Ethiopia; \\ ${ }^{3}$ Department of Pediatrics and Child \\ Health, College of Health Sciences, Addis \\ Ababa University, Addis Ababa, Ethiopia
}

Correspondence: Arega Gashaw Tsige Email arega.gashaw@mu.edu.et

\begin{abstract}
Purpose: Irrational antibiotic use is a worldwide problem. One of the main reasons for excessive use of antibiotics is the failure to follow the clinical guidelines. Inappropriate use of antibiotics for infectious diarrhea is associated with the risk of increasing the development of antimicrobial resistance and the cost of health care. We therefore pursued to assess the appropriateness of the management of diarrhea in children in Addis Ababa.
\end{abstract}

Materials and Methods: A retrospective cross-sectional study was conducted in the health centers of Addis Ababa, Ethiopia, between September 2014 and February 2015. Demographic characteristics, signs of dehydration, stool characteristics, drug types and other relevant information have been collected. Data analysis was performed using version 20 of the SPSS. Logistic regression was used to examine the association between dependent and independent variables. Indicators for the appropriateness of diarrhoea management have been established on the basis of the Standard Treatment Guideline and the guidelines of the World Health Organization.

Results: A total of 803 medical records of children have been checked. Of this, $54.4 \%$ had received inappropriate management. At least one antimicrobial was prescribed to $73.2 \%$ of the children who visited the health centres. Oral rehydration solution (ORS) and zinc were prescribed only in $66.7 \%$ and $47.5 \%$, respectively. Appropriate management among children diagnosed with dysentery was found to be 6.38 times higher adjusted odds ratios (AOR=6.38 $(3.11,13.63))$ than children with watery diarrhea. Although antibiotics are prescribed inappropriately for most children, it is appropriate when the diarrhea is bloody. Appropriate management of diarrhoea among infants aged 2-11 months was $54 \%$ less compared to children aged $12-59$ months $(\mathrm{AOR}=0.46(0.24,0.90))$.

Conclusion: The magnitude of inadequate antibiotic prescription while managing diarrhoea in our setting was high. On the contrary, a low prescribing rate of ORS and zinc was observed. Our result highlights the need for urgent action to prevent the development of antibiotic-resistant microorganisms. Health-care professionals should have clear information on the risks of inadequate diarrhoea treatment in children under five.

Keywords: under-five children, diarrhoea management, antimicrobial

\section{Introduction}

Diarrhoea and its complications (dehydration and malnutrition) remain a major cause of hospitalization and death among children. ${ }^{1}$ According to WHO and UNICEF report, there are around two billion instances of diarrheal disease worldwide and 1.9 million children younger than 5 years of age dying from diarrhoea each year. ${ }^{2}$

The management of a child presenting with diarrhoea should include a thorough history and examination in line with an evaluation of hydration and nutritional status, and subsequently, a complete scientific assessment for complications is 
required. This implies information about ethology and appropriate management is fundamental. ${ }^{1}$ Once this examination and evaluation have been completed, a decision then needs to be made in terms of the method of rehydration, feeding, and besides, if there are signs for any specific examinations that ought to be attempted. Adequate fluid and electrolyte replacement and maintenance are critical to overseeing diarrheal disease. ${ }^{3}$

As the vast majority of the diarrhoea cases are viral and self-limiting, the pillar of diarrhoea management is an oral rehydration solution (ORS) and antibiotics have less value. ${ }^{4-6}$ Despite this fact, health care providers commonly prescribe antibiotics to treat diarrhoea in under-five children worldwide. $^{7,8}$ Such misuse of antibiotics has become a global issue, with the emergence of deadly infections caused by multidrug-resistant strains. These infections greatly affect the quality of life and put a high economic burden, as a result, both direct and indirect costs.

The issues of antimicrobial misuse are of global concern; not only because of developing resistance but also due to the escalating health care costs caused by overuse of antibiotics. The major consequence of the excessive use of medications is adverse medical outcomes that cause significant morbidity and mortality. ${ }^{9-12}$

Irrational utilization of medication has been comprehended to be a significant problem in the Ethiopian health care system. Therefore, the Integrated Management of New-born and Childhood Illness (IMNCI) assessment chart is currently advocated to be used in all health centres and health posts throughout the country. Health care providers trained thoroughly on how to use it. In addition to this, the use of national standard treatment guidelines and national drug formulary, together with WHO guidelines are advocated especially in settings where there are no available laboratory services and high patient overload. ${ }^{13-15}$

Prior studies; done to assess the management of diarrhoea in under-five children were hospital-based and have a small sample size. Majority study on prevalence but his study was done at health centre levels with large sample size and with indicators of the appropriateness of diarrhoea management. Therefore, we aimed to assess the appropriateness of diarrhoea management against the STG and WHO guidelines in Addis Ababa.

\section{Materials and Methods}

This study was carried out at 14 of the 85 public health centres which operate under the Addis Ababa City Administration. The city administration has a total of 10 sub-cities, and the sampled health centres were selected from 4 sub-cities as shown in Figure 1. The health centres receive financial support from the government to provide services free of charge. The study was conducted in September 2014 and February 2015.

\section{Ethical Consideration}

Ethical approval for the study was granted by the Institutional Review Board of Addis Ababa University School of Pharmacy with reference number ERB/SOP/ $42 / 02 / 2015$. Permission to collect the data was also obtained from Addis Ababa city health administration bureau and respective district health facilities.

\section{Design}

The cross-sectional study design was used for this study. The source of the population included under-five children who presented with diarrheal illness in all health centres. The study population was composed of children with diarrhoea who visited randomly selected health centres during the study period. An appropriate data extraction format was determined that would meet the objectives of the study after reviewing the literature and the WHO guidelines. Data extracted from IMNCI assessment and classify chart booklet included demographic characteristics (age, gender), medical characteristics (chief child complainants, the presence of danger sign (unable to feed, vomit everything, convulsion and unconscious), and a sign of dehydration, stool characteristics, type of diarrhoea, the type of drug used) and the appropriateness of the management is evaluated according to indicators as shown in Table 1.

\section{Eligibility Criteria}

The study's inclusion criteria were composed of children above two months old and under-five years of age with diarrhoea who visited health centres.

Infants younger than two months of age and older than five years of age and those who have diarrheal lasting more 14 days as well as those with incomplete patient data were excluded.

\section{Sample Size and Recruitment}

A multi-stage sampling method was used to determine the sample size. The sample size was drawn by using the Hayes and Bennett formula. ${ }^{16}$ Simple proportion sampling method was used by taking prevalence $50 \%$ since there is no previous prevalence study to estimate 


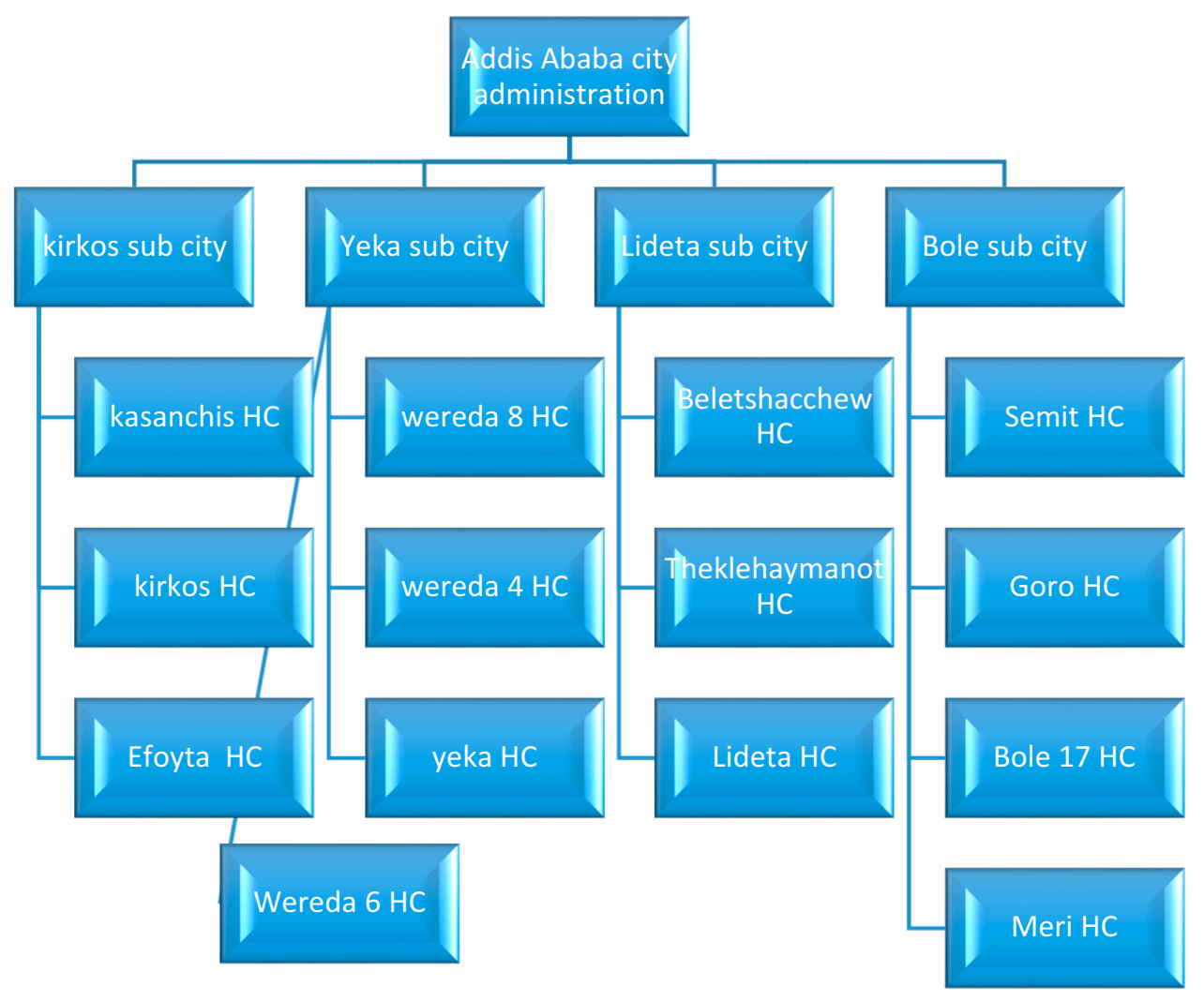

Figure I Multistage sampling of the health centers from the 10 sub cities of Addis Ababa city administration.

P. The sample size calculated was 384 . We added $10 \%$ for contingency, which gave a sample size of 422 . A design effect of 2 was used to ensure that the sample plan achieves an optimum balance that seeks to

Table I Indicators of Inappropriateness of the Management of Children with Diarrhoea Based on IMNCI Guidelines

\begin{tabular}{|c|c|c|}
\hline & Number & Percentage \\
\hline $\begin{array}{l}\text { Child received an antibiotic that was not } \\
\text { needed }\end{array}$ & 216 & 27.9 \\
\hline $\begin{array}{l}\text { Children received antidiarrheal agent } \\
\text { that was not needed }\end{array}$ & 42 & 5.6 \\
\hline $\begin{array}{l}\text { Children needing ORS that was not } \\
\text { received }\end{array}$ & 270 & 33.7 \\
\hline $\begin{array}{l}\text { Children needing zinc supplement that } \\
\text { was not received }\end{array}$ & 421 & 52.5 \\
\hline $\begin{array}{l}\text { Children needing antibiotics that were } \\
\text { not received }\end{array}$ & 78 & 9.7 \\
\hline $\begin{array}{l}\text { Children with persistent diarrhea that } \\
\text { was not received at least one dose of } \\
\text { Vitamin A at its therapeutic dose }\end{array}$ & 2 & 2 \\
\hline $\begin{array}{l}\text { Child with diarrhea incorrectly managed } \\
\text { for diarrhea }\end{array}$ & 437 & 54.4 \\
\hline
\end{tabular}

minimize costs while maximizing precision since we use multistage cluster sampling and therefore the total sample size was estimated to be $845 .{ }^{17}$

Four out of the ten sub-cities of Addis Ababa city administration were selected using simple random sampling by simple lottery methods. Fourteen health centres from within those four sub-cities selected using lottery methods Figure 1. The number of health centres in each sub-city was determined by a quota based on the number of health centres available in the sub-cities. Patient cards were from each health centres selected by systematic random sampling methods.

\section{Data Processing and Analysis}

Pre-tests were done before the actual data collection on 5\% of the children. Data were collected by two trained nurses. Data was collected from the IMNCI chart booklet and children medical records. The data was checked, sorted it, and then reviewed it manually for errors and data incompleteness. Epi data for data entry and SPSS 20 was used for data analysis. Frequencies and percentages were calculated to describe findings while binary logistic regression was performed to look for an association between dependent and non-dependent variables. Those variables that showed 
a p-value $<0.25$ with outcome variables in the bivariate analysis and deemed to be important from the previous study (sex and age) were selected as candidate variables for multivariable logistic regression analysis. $\mathrm{P}$ values less than 0.05 were considered to be statistically significant.

\section{Results}

Among 803 children, 365 (45.5\%) were female. The median age of the patients was found to be 23.1 months with interquartile range (IQR) 11-21 months.

The majority of the children (99.1\%) was vaccinated according to the national immunization schedule based on their age, and $0.9 \%$ of the children were a defaulter of vaccinations with unknown reason and $84.4 \%$ and $45.4 \%$ of children received Vitamin A and Albendazole respectively as shown in Table 2 .

The mean time elapsed between the onset of diarrhoea and visiting of a health centre was $2.58+1.24$ days, and the mean frequency of passing stool per day was $3.90+$ 0.83 . The number of children that were assessed the acute type of diarrhoea and watery type of diarrhoea was $86.9 \%$ and $78.8 \%$, respectively.

Of the children that were assessed based on the signs and symptoms of dehydration, the physical examinations revealed that only $2.7 \%$ of children had some dehydration, whereas $97.2 \%$ had no signs of dehydration. From the total children who visit the health centres, acute upper respiratory

Table 2 Characteristics of Children Visiting the Health Centres in Addis Ababa

\begin{tabular}{|l|l|l|}
\hline \multicolumn{2}{|l|}{ Demographic Variables } & Number (\%) \\
\hline Sex & Male & $438(54.5)$ \\
& Female & $365(45.5)$ \\
\hline Age & $2-1$ I months & 27 I (33.7) \\
& I2-59 months & $532(66.3)$ \\
\hline Vaccination status & Complete & $586(83.2)$ \\
& Up-to-date & $112(15.9)$ \\
& Default & $6(0.9)$ \\
\hline Vitamin A administration & Up-to-date & $429(84.4)$ \\
& Not up-to-date & $6(1.2)$ \\
& Not a candidate & $73(14.4)$ \\
\hline \multirow{2}{*}{ Albendazole administration } & Up-to-date & $247(45.4)$ \\
& Not up-to-date & $24(4.4)$ \\
& Not taken at all & $3(0.6)$ \\
& Not a candidate & $270(49.6)$ \\
\hline
\end{tabular}

Notes: NB: not a candidate $=$ those who have taken the medication previously and do not need to take the medication now or contraindicated for the prescribed drugs; up-to-date = the child always takes the medication according to schedules. tract infection (AURTI) (23\%) and pneumonia (2.6\%) were the common comorbid illness in the children who presented with diarrhoea. Routine microscopic examinations were done for $37.4 \%$ of the children. $326(40.6 \%)$ of the children with diarrhoea complained of watery stools, as shown in Table 3.

Of the 803 episodes of diarrhoea, $92.5 \%$, children were being given a pharmacological intervention (giving drugs, including ORS and zinc for the treatment of diarrhoea). At least one antimicrobial was prescribed to $73 \%$ of all children.

Antimicrobials were prescribed to $86.6 \%$ of the children who presented with diarrhoea. Antimicrobial, ORS, and zinc were co-administered in $20.2 \%$ of them, whereas in $22.9 \%$ of cases antimicrobials were given alone see Table 4. Zinc and ORS were not usually prescribed alone.

The number of drugs for the treatment of diarrheal episodes per prescription is presented in Table 5. The mean number of drugs per prescription was $2.3+1.36$ whereas the mean number of drugs per prescription containing three or more drugs was $3.9+0.8$ as shown in Table 5 .

Table 3 Characteristics of Diarrhea, Clinical and Laboratory Findings of the Children

\begin{tabular}{|c|c|c|c|}
\hline & Variable & Number & Percentage \\
\hline $\begin{array}{l}\text { Characteristic } \\
\text { of stool }\end{array}$ & $\begin{array}{l}\text { Watery } \\
\text { Bloody }\end{array}$ & $\begin{array}{l}379 \\
102\end{array}$ & $\begin{array}{l}78.8 \\
21.2\end{array}$ \\
\hline $\begin{array}{l}\text { Duration of } \\
\text { diarrhea }\end{array}$ & $\begin{array}{l}\text { Acute }<14 \text { days } \\
\text { Persistent }>14 \text { days }\end{array}$ & $\begin{array}{l}698 \\
105\end{array}$ & $\begin{array}{l}86.9 \\
13.1\end{array}$ \\
\hline $\begin{array}{l}\text { Presence of } \\
\text { dehydration }\end{array}$ & $\begin{array}{l}\text { No dehydration } \\
\text { Some dehydration } \\
\text { Severe dehydration }\end{array}$ & $\begin{array}{l}634 \\
18(2.2) \\
0(0)\end{array}$ & $\begin{array}{l}97.2 \\
2.8 \\
0.0\end{array}$ \\
\hline Symptoms & $\begin{array}{l}\text { Vomiting } \\
\text { Fever } \\
\text { Abdominal pain } \\
\text { Vomiting + fever } \\
\text { Vomiting+ abdominal } \\
\text { pain } \\
\text { Fever + abdominal } \\
\text { pain } \\
\text { Vomiting +fever + } \\
\text { abdominal pain }\end{array}$ & $\begin{array}{l}475 \\
175 \\
84 \\
109 \\
61 \\
16 \\
11\end{array}$ & $\begin{array}{l}59.2 \\
21.8 \\
10.5 \\
13.6 \\
7.6 \\
2 \\
1.4\end{array}$ \\
\hline $\begin{array}{l}\text { Comorbid } \\
\text { illness }\end{array}$ & $\begin{array}{l}\text { Pneumonia } \\
\text { Upper respiratory } \\
\text { infection } \\
\text { Malnutrition }\end{array}$ & $\begin{array}{l}21 \\
185 \\
11\end{array}$ & $\begin{array}{l}2.6 \\
23 \\
1.4\end{array}$ \\
\hline Laboratory & $\begin{array}{l}\text { Microscopy (Stool } \\
\text { examination) } \\
\text { Blood culture }\end{array}$ & $\begin{array}{l}300 \\
2\end{array}$ & $\begin{array}{l}37.4 \\
0.25\end{array}$ \\
\hline
\end{tabular}


Table 4 Prescribing Patterns for Treatment of Diarrheal Episodes

\begin{tabular}{|l|l|}
\hline & Number (\%) \\
\hline Antimicrobial only & $184(22.9)$ \\
Antimicrobial + ORS & $125(45.6)$ \\
Antimicrobial + ORS+ zinc & $162(20.2)$ \\
Antimicrobial + ORS+ zinc + other drugs & $82(10.2)$ \\
Antimicrobial and other drugs & $52(6.4)$ \\
ORS only & $27(3.4)$ \\
ORS and zinc only & $0(0)$ \\
\hline
\end{tabular}

Table 5 Number of Drugs Prescribed for Children with Diarrhea Among Children

\begin{tabular}{|l|l|}
\hline Prescription Characteristics (Number of Drugs) & Number (\%) \\
\hline 0 (No drug) & $60(7.5)$ \\
1 & $194(24.1)$ \\
2 & $156(19.4)$ \\
3 & $260(32.3)$ \\
4 & $84(10.4)$ \\
5 & $36(4.5)$ \\
6 & $14(1.7)$ \\
\hline
\end{tabular}

ORS and Zinc are included in the above table. The pattern of the drugs prescribed for the children as it is shown in Table 5.

The drugs prescribed for the treatment of the diarrheal episodes are presented in Figure 2. Cotrimoxazole was prescribed for the majority of the children $(70.7 \%)$ who presented with diarrhoea whereas metronidazole $(7 \%)$ and amoxicillin $(4.6 \%)$ were less commonly prescribed drugs. ORS was prescribed to $66.7 \%$ of the children, whereas zinc was prescribed to $43.8 \%$ of the children within the study (Figure 3). Antiemetics (Metoclopramide) were prescribed for $7 \%$ of the children, but no antidiarrheal drugs were prescribed.
The prescription rates of antibiotics were changed in magnitude as dehydration status and persistent diarrhoea increased. All children who presented with persistence diarrhoea received antibiotics (Figure 3).

A relatively high percentage of metronidazole was prescribed in cases of diarrhoea with no dehydration than in the cases of dysentery diarrhoea. Co-administration of metronidazole and cotrimoxazole were rare (Figure 3).

The prescription rates of antibiotics were changed in magnitude when the children presented with diarrhoea and other comorbid illness as shown in Figure 4. With respect, the WHO guidelines, $45.6 \%$ of children reviewed in this study have received appropriate management of diarrhoea.

Regarding appropriate management based on stool characteristics, children with bloody diarrhoea 6.38 times more likely to receive appropriate diarrhoea management compared to children with mucous diarrhoea and the odds of appropriate management of diarrhoea for children with watery diarrhoea were $77 \%$ less compared to children with mucous diarrhoea (Table 6) and based on the indicators of inappropriateness of the management of children with diarrhoea (Table 1).

The odds of appropriate management of diarrhoea for infants aged 2-11 months were $54 \%$ less compared to children 12-59 months as shown in Figure 5. Indicators of the inappropriateness of the management of children with diarrhoea seen in Table 1.

\section{Discussion}

Although routine use of antibiotics for infectious diarrhoea in children is discouraged except in selected cases (dysentery, cholera, and giardiasis) as it has little benefit in most cases and is associated with the risk of increasing antimicrobial resistance. Our study showed that the proportion of

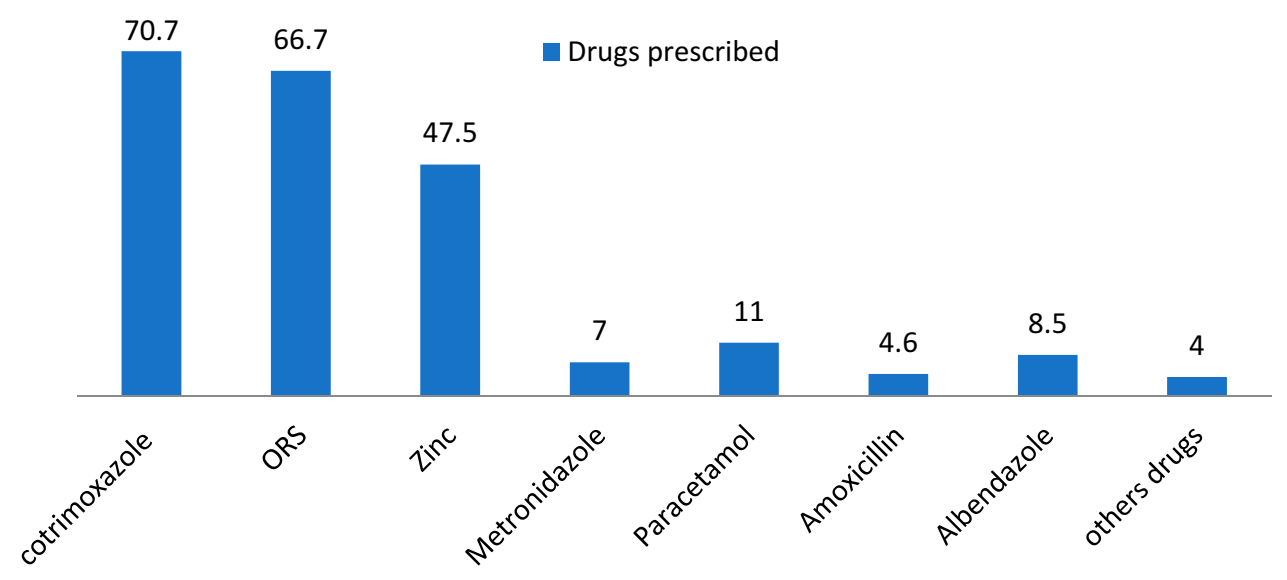

Figure 2 Drugs prescribed for the treatment of diarrheal episodes in health centers. 
cotrimoxazole metronidazole Both

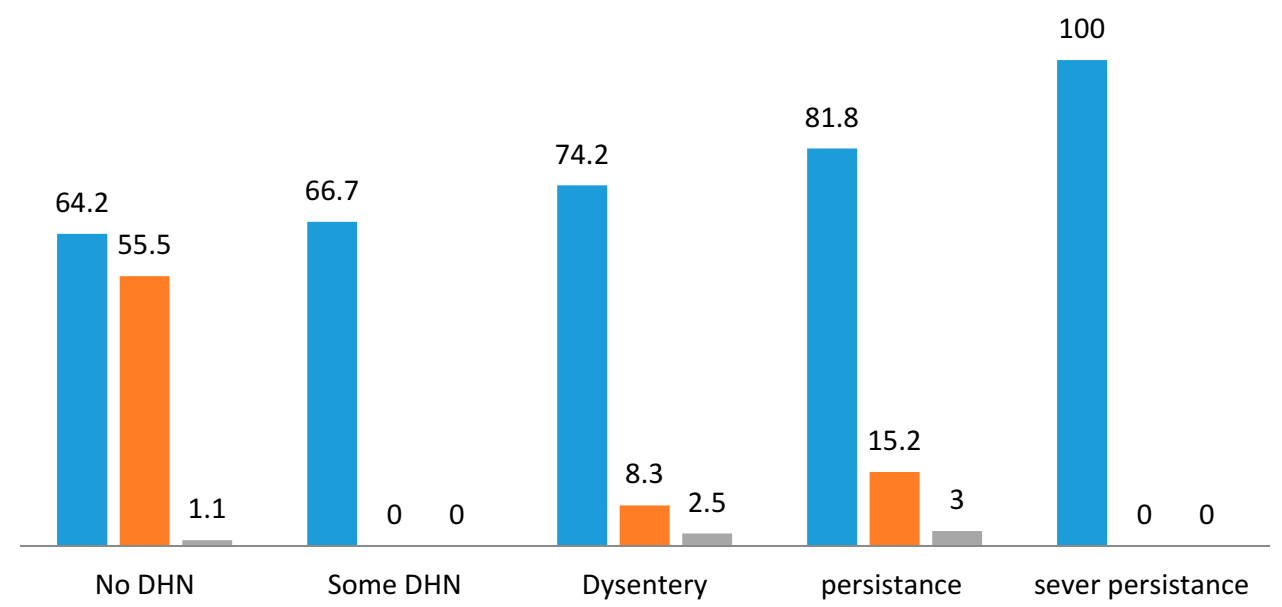

Figure 3 The drug prescription patterns based on clinical classification of the disease in health center.

antimicrobial given antimicrobial not given

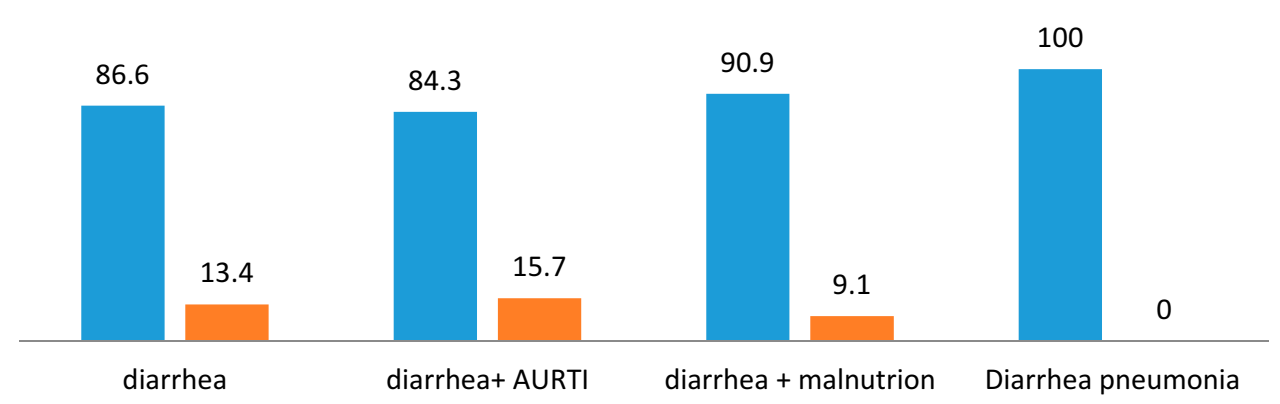

Figure 4 Proportion of antibiotics according to comorbid illness.

antibiotics prescribed per prescription was $86.6 \%$. This proportion is similar to that reported in other studies in Tanzania and India, where the proportion of antibiotic use ranged from $69.0 \%$ to $89 \%$. $^{2,8,14,18-20}$

We found that $73.2 \%$ of children with diarrhoea were given at least one form of antibiotic and this finding has shown that the standard of diarrhoea treatment is consistent with the National Standard Treatment Guideline and WHO Guidelines, and is consistent with a cross-sectional descriptive hospital study in Tanzania that identified $71.5 \%$ of all prescriptions in Tanzania. However, this was different from the study in India which reported that at least one antibiotic was prescribed for 43-69 per cent of children. ${ }^{8}$ This unreserved use of antibiotics may result in antibiotic resistance. Also, antibiotics are costly, hence, money is wasted where the use of antibiotics is unrestricted.
Cotrimoxazole was prescribed for the majority of the children $(70.7 \%)$ who presented with diarrhoea whereas metronidazole (7\%) and amoxicillin (4.6\%) were less commonly prescribed drugs. This result is in contrast to the study found by the University of Nigeria teaching hospital where cotrimoxazole was only prescribed $7.5 \%{ }^{21}$ of the time. Other studies were done in New Delhi and Ujjain, India showed ciprofloxacin and ampicillin were commonly used antibiotics to manage children with diarrhoea. ${ }^{8,18}$ This may be due to the difference in availability, resistance profile and recommendation of the drug in the guidelines in each country.

Inappropriate and overuse of antibiotics for diarrhoea is a major contributing factor towards increasing rates of antimicrobial resistance. These practices have probably not led to improvements in health and may have promoted the emergence and persistence of drug-resistant. While; 
Table 6 Association of Appropriate Management of Diarrhea and Demographic Characteristics of the Child and Stool Characteristics in Health Centers

\begin{tabular}{|c|c|c|c|c|c|}
\hline \multicolumn{2}{|l|}{ Variable } & \multicolumn{2}{|c|}{ Appropriate Management } & \multirow{3}{*}{$\begin{array}{l}\text { COR } \\
\begin{array}{l}0.056(0.041,0.75) \\
1.00\end{array}\end{array}$} & \multirow{3}{*}{$\begin{array}{l}\text { AOR } \\
0.46(0.24,0.90) \\
1,00\end{array}$} \\
\hline & & \multirow{2}{*}{$\begin{array}{l}\text { NO (\%) } \\
173(63.8) \\
264(49.6)\end{array}$} & \multirow{2}{*}{$\begin{array}{l}\text { Yes (\%) } \\
98(36.2) \\
268(50.4)\end{array}$} & & \\
\hline Age of child & $\begin{array}{l}2-11 \text { months } \\
12-59 \text { months }\end{array}$ & & & & \\
\hline Sex of child & $\begin{array}{l}\text { Male } \\
\text { Female }\end{array}$ & $\begin{array}{l}256(70.1) \\
312(7 I .2)\end{array}$ & $\begin{array}{l}109(29.9) \\
126(28 .)\end{array}$ & $\begin{array}{l}1.07(0.81,1.42) \\
1.00\end{array}$ & $\begin{array}{l}\text { I.09 }(0.74,1.6) \\
1.00\end{array}$ \\
\hline Stool characteristics & Watery diarrhoea & I $64(70.4)$ & $69(29.6)$ & $0.5 \mathrm{I}(0.028,0.94)$ & $0.23(0.13,0.88)$ \\
\hline
\end{tabular}

Abbreviations: COR, crude odds ratios; AOR, adjusted odds ratios.

ORS and Zinc are recommended regardless of the causative agent and age of the patient unless the patient is comatose or severely dehydrated, having severe malnutrition $(12,25)$; but our study shows ORS and zinc were prescribed only to $66.7 \%$ and $43.8 \%$ of under-five children who had diarrhoea. This result was comparable with the hospital-based descriptive study completed in Tanzania, ${ }^{14}$ although it is considerably lower than similar studies done in Bahrain, Kashmir and Kenya. ${ }^{12,22,23}$ The result of this study also contradicts to other cross-sectional study conducted in Hawassa University Teaching and Referral Hospital, Ethiopia that showed that $90 \%$ coverage of treatment with ORS and zinc supplements for children with diarrhoea. ${ }^{24}$ This difference may be due to the difference in hospital-based (Hawassa) verses in health centre study.

Antidiarrheal and anti-emetics (Metoclopramide) were prescribed for the treatment of diarrhoea $0 \%$ and $7 \%$ respectively. This result is not aligned with the study done in Baghdad that indicates anti-diarrheal and antiemetics drugs were used in $12.8 \%$ and $33.2 \%$ of the cases respectively (29). Studies were done in Bahraini reports $7 \%$ and $12 \%$ of anti-diarrheal (Loperamide) and anti-emetics (Promethazine, prochlorperazine) were used respectively. ${ }^{15}$ These drugs not only have no benefit in diarrhoea treatment but may also cause serious, even life-

\section{Management of diarrhea}

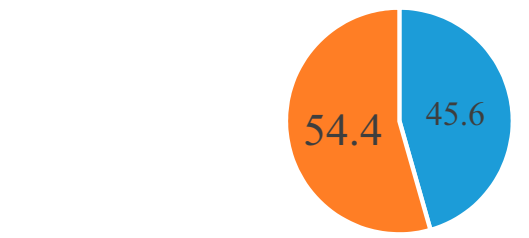

- appropriate management of diarrhea

- poor management of diarrhea

Figure 5 The prevalence of appropriate management in health center. threatening side effects in children. It may be considered as harmful practices in the management of childhood diarrhoea. ${ }^{25}$ While antibacterial agents have no proven usefulness in the management of in majority cases acute watery diarrhoea, ${ }^{26}$ many health professionals continue to use them extensively, as was seen in this study.

The WHO guidelines both recommend antimicrobials for all children with bloody diarrhoea, cholera, and giardiasis. ${ }^{27}$ Antimicrobials were prescribed for all children $(100 \%)$ when the children presented with pneumonia in addition to diarrhoea and $90 \%$ of children who presented with both malnutrition and diarrhoea. This result aligns with the hospital-based study conducted in Moshi municipal, Tanzania where $84.5 \%$ of antibiotics were prescribed for children presented with both malnutrition and diarrhoea. ${ }^{28}$

Only $45.6 \%$ of the children who visited the health centres were appropriately managed for diarrhoea. This result is in contrast to a study which consisted of a crosssectional survey in a random sample of 938 health posts in Oromia, Ethiopia that reveals $79 \%$ of children with diarrhoea were correctly managed. ${ }^{29}$

In this study, there was a relatively short period between the onsets of diarrhoea and when the child was taken to health centres $(2.58+1.24$ days $)$ and the majority of the children $(97.2 \%)$ who visited the health centres presented with no sign of dehydration. And $99.1 \%$ of the children are vaccinated according to the national immunization schedules including Rotavirus; the main cause of diarrhoea in children. ${ }^{30}$

Diarrheal can be exacerbated by micronutrient malnutrition. Research shows that Vitamin A supplementation every 6 months reduces the mortality rate by $23 \%$ among children 6-59 months of age and reduces the severity of diarrhoea. ${ }^{31}$ Both of these are important considerations. Plausible explanations for these findings may be related 
to the community awareness about diarrhoea and its hazards as well as the health-seeking behaviour of the population.

The study has the following limitations. First, it was conducted in 14 public health centres in Addis Ababa; where severe and complicated diarrhoea disease less likely seen, so any effort to extrapolate the results beyond the study population should be made with caution. Second, since the data was collected from IMNCI assess and classify chart booklet retrospectively, there is a potential that incomplete or missing documentation, poorly recorded and absent information also limited the results of this study. Besides, extracted data may not reflect the medication prescribed and taken. Third, the factor is that magnify or compromised the management is not addressed by this study.

\section{Conclusion}

This study has revealed the unreserved use of antibiotics and underutilization ORS and zinc supplementation for the treatment of diarrhoea in Addis Ababa, Ethiopia. This demonstrates that both Standard treatment guideline and WHO guidelines are not strictly being followed by health professionals. Cotrimoxazole was the most commonly prescribed antibiotic by the health professionals in the health centres. Overuse of antimicrobials without clinical indication may lead to antibiotic resistance and resource loss. It is vital to teaching health professional about the danger of inappropriate management of diarrhoea in children under five.

\section{Ethics and Consent Statement}

Ethical approval for the study was granted by the Institutional Review Board of Addis Ababa University School of Pharmacy with reference number ERB/SOP/ 42/02/2015. Permission to collect the data was also obtained from Addis Ababa city health administration bureau and respective district health facilities. The information from the patient cards was kept confidential, only the data collector had the access to information, which talks about the patient information other than the topic of interest. We conduct our studies after we have had a parent or legal guardian of the children provided written informed consent and in compliance with the principles of the Declaration of Helsinki.

\section{Acknowledgments}

We would like to acknowledge Mekelle University for providing a scholarship for the first author for his postgraduate study. We also are grateful for Addis Ababa University and Addis Ababa health bureau administration, and staff of each health centre for supporting this research to be conducted.

\section{Author Contributions}

All authors contributed to data analysis, drafting or revising the article, gave final approval of the version to be published, and agree to be accountable for all aspects of the work.

\section{Funding}

The study settings, College of Health Sciences, and Black Lion Tertiary Specialized Hospital have contributed material support to this study.

\section{Disclosure}

All authors declare that they have no conflicts of interest.

\section{References}

1. Ml C. Causes and management of diarrhoea in children in a clinical setting. Africa J Clin Nutr. 2010;23(1):42-46. doi:10.1080/16070 658.2010.11734269

2. Farthing M, Salam MA, Lindberg G, et al. Acute diarrhea in adults and children: a global perspective. J Clin Gastroenterol. 2013;47 (1):12-20. doi:10.1097/MCG.0b013e31826df662

3. Guerrant RL, Van Gilder T, Steiner TS, et al. Practice guidelines for the management of infectious diarrhea. DSA Guidelines. CID. 2001. p. 331-351.

4. Pires SM, Fischer-Walker CL, Lanata CF, et al. Aetiology-specific estimates of the global and regional incidence and mortality of diarrhoeal diseases commonly transmitted through food. PLoS One. 2015;10(12):1-17. doi:10.1371/journal.pone.0142927

5. Killer G. Global Diarrhea Burden. Centers Dis Control Prev. 2013;1-4.

6. Services H. Diarrhea: Common Illness. Global Killer:1-4.

7. Mahapatra T, Mahapatra S, Banerjee B, Mahapatra U. Predictors of rational management of diarrhea in an endemic setting: observation from India. PLoS One. 2015;1-13.

8. De Jong J, Van Den Berg PB, Visser ST, De Vries TW, De Jong-van Den Berg LT. Antibiotic usage, dosage and course length in children between 0 and 4 years. Acta Paediatr Int J Paediatr. 2009;98 (7):1142-1148. doi:10.1111/j.1651-2227.2009.01309.x

9. Kotwani A, Chaudhury RR, Holloway K. Antibiotic prescribing practices of primary care prescribers for acute diarrhea in New Delhi, India. Value Heal. 2012;15(1):S116-9. doi:10.1016/j. jval.2011.11.008

10. Chilongola J, Msoka E, Juma A, Kajeguka DC, Semvua H. Antibiotics prescription practices for provisional malaria cases in three hospitals in Moshi, northern Tanzania. Tanzan J Health Res. 2015;17(3):1-10.

11. Carlet J. Overcoming global anti microbial resistance. Global Health Dyn. 2015;5-29 p.

12. Ismaeel AY, Al Khaja KAJ, Damanhori AHH, Reginald P, Botta GA. Management of acute diarrhoea in primary care in bahrain: self-reported practices of doctors. J Heal Popul Nutr. 2007;25 (2):205-211.

13. DACA. Standard treatment guideline for health centers: drug administration and control authority of Ethiopia. 2010;January:1-349. 
14. Gwimile JJ, Shekalaghe SA, Kapanda GN, Kisanga ER. Antibiotic prescribing practice in the management of a cough and/or diarrhea in Moshi Municipality, Northern Tanzania: cross-sectional descriptive study. Pan Afr Med J. 2012;12:103.

15. FMOH W. Integrated management of newborn and childhood illness, part 2. Module. 2012;2(2).

16. WHO. Integrated Management of Childhood Illness: Caring for the Sick Child in the Community. WHO Libr [Internet]; 2011.1-21.

17. Hayes RJ, Bennett S. Simple sample size calculation for cluster-randomized trials. Int J Epidemiol. 1999;28(2):319-326. doi:10.1093/ije/28.2.319

18. Sharma M, Eriksson B, Marrone G, Dhaneria S, Lundborg CS. Antibiotic prescribing in two private sector hospitals; one teaching and one non-teaching: a cross-sectional study in Ujjain, India. Bio Med Cent. 2012;12:1-9.

19. Diniz-santos DR, Silva LR, Silva N. Antibiotics for the empirical treatment of acute infectious diarrhea in children. Braz J Infect Dis. 2006;10(3):217-227. doi:10.1590/S1413-86702006000300011

20. $\mathrm{Xu} \mathrm{S}$, Huang $\mathrm{H}$, Li G. Clinical practice guidelines for clostridium difficile infection in adults: 2010 update by the society for healthcare epidemiology of america (SHEA) and the infectious diseases society of America (IDSA). Soc Health Epidemiol Am. 2011;11(6):426-427.

21. Emodi IJ, Paed F. Medication use and abuse in childhood diarrhoeal diseases by caregivers reporting to a Nigerian tertiary health institution. Sajch J Child Heal. 2009;3(3):83-88.

22. Grant AR, Kebaya L. The recognition, assessment and management of diarrheal illness in children under 5 years at the community and health facility level in Kisii, Kenya. Seattle Child Hosp Res Found. 2013;1-27
23. Desalegn AA. Assessment of drug use pattern using WHO prescribing indicators Hawassa University teaching and referral hospital, south Ethiopia: a cross-sectional study. BMC Heal Serv Res. 2013;1-6.

24. Wardlaw T, Salama P, Brocklehurst C, Chopra M, Mason E. Diarrhoea: why children are still dying and what can be done. Lancet. 2010;375 (9718):870-872. doi:10.1016/S0140-6736(09)61798-0

25. Child DOF, Health A. Policy guidelines on control and management of diarrhea diseases in children below five years in Kenya. Minist Public Heal Sanit. 2010;1-11.

26. Lafta RK, Al-shatari SAE, Hassan RA. Drug misuse in the treatment of diarrhea among children under five years; a Sample from Baghdad. Iraqi J Common Med. 2014;1:14-18.

27. Carter E, Bryce J, Perin J, Newby H. Harmful practices in the management of childhood diarrhea in low- and middle-income countries: a systematic review [Internet]. BMC Public Health. 2015;15: 788-822. doi:10.1186/s12889-015-2127-1

28. Heidelbaugh J. Diarrhea and dehydration. Text B Fam Med. 2011; $1-30$.

29. Access O. Antibiotic prescribing practice in the management of a cough and/or diarrhea in Moshi Municipality, Northern Tanzania: cross-sectional descriptive study. Pan Afr Med J. 2012;12(103):1-8.

30. Miller $\mathrm{N}$, et al. Utilization of ICCM services: federal ministry of health of Ethiopia. 2013;1-4.

31. Fischer Walker CL, Black RE. Micronutrients and diarrheal disease. Clin Infect Dis. 2007;45(Suppl 1):S73-S77. doi:10.1086/518152
Pediatric Health, Medicine and Therapeutics

\section{Publish your work in this journal}

Pediatric Health, Medicine and Therapeutics is an international, peerreviewed, open access journal publishing original research, reports, editorials, reviews and commentaries. All aspects of health maintenance, preventative measures and disease treatment interventions are addressed within the journal. Practitioners from all disciplines are invited to submit their work as well as healthcare researchers and patient support groups. The manuscript management system is completely online and includes a very quick and fair peer-review system. Visit http://www.dovepress.com/testimonials.php to read real quotes from published authors. 